\title{
THE CALORIC VALUE OF LABILE BODY TISSUE IN OBESE SUBJECTS
}

\author{
By VINCENT P. DOLE, IRVING L. SCHWARTZ, NIELS A. THORN, AND \\ LAWRENCE SILVER \\ (From the Hospital of The Rockefeller Institute for Medical Research, New York. N. Y.)
}

(Submitted for publication September 16, 1954; accepted December 1, 1954)

The caloric balance normally varies from moment to moment. Food is taken intermittently, absorbed, stored, and used as needed for the continuous requirements of metabolism. Variations of diet and of physical activity on successive days cause temporary inequalities of energy intake and output. Long-term balance requires some system to smooth these fluctuations.

In the present work we have endeavored to define one aspect of the system by correlating small changes in body weight with known variations of caloric intake. The ratio of these two quantities - the caloric equivalent of labile body weightsets an upper limit to the energy value of primary storage tissue.

The caloric equivalent would be easy to measure if all changes in weight were due to caloric imbalance. In reality, however, various other processes-menstrual changes or venous congestion, for instance-cause body fluid to vary without relation to the caloric status of the individual. Any single measurement of energy balance and weight change fails to define the caloric equivalent because it provides no means to distinguish a specific change of weight from an accidental fluctuation of water balance.

Measurement of the total fluid balance cannot resolve the difficulty, however, because a considerable amount of water is held intracellularly with glycogen and protein. If these substances are used for temporary storage of energy their accumulation and discharge will cause an obligate variation of fluid balance, quantitatively related to each caloric change, and thus part of the caloric equivalent. Possibly the volume of extracellular fluid also varies with the caloric response. In any case, the distinction between caloric and noncaloric changes of hydration can be made only by repetition of the measurement, since a specific response to caloric variation is defined solely by the fact of its consistent occurrence.
Standard methods for measurement of heat production-a calorimeter room (1) or an exact determination of water loss (2)-would be inconvenient for use in prolonged experiments such as are required by repeated changes of dietary intake. Fortunately, the average energy balance and the caloric equivalent can be measured more easily, and with greater accuracy, by an analysis of the weight response alone. Two known levels of dietary intake are equivalent in this case to the usual pair of data: one known level of intake and the measured rate of heat production. An additional advantage of the method is that it measures the caloric equivalent and the average daily requirement for maintenance under conditions that simulate normal variations of diet.

\section{METHODS}

Five obese but otherwise healthy women remained on the metabolic ward during the entire study. Each morning, after they had voided, a nurse weighed them on calibrated scales with a beam graduated in divisions of $100 \mathrm{gm}$. During the day they followed the usual routine of the ward: rest hour at 1 P. M., bedtime at 10 P. M.; walking, reading and light handiwork within the confines of ward and porch at other times. Their physical activity under these conditions appeared to remain nearly constant from day to day.

They were fed with a formula of constant composition (Table I) given in six equal portions at 7 and $10 \mathrm{~A}$. M., $1,4,7$, and 10 P. M. With a vitamin supplement 1 this and similar formulas have sufficed as the sole nutriment in a variety of studies (3), some lasting as long as eight months. The present group of patients took the formula during the six to eight weeks of this study, and then continued with the feeding for an additional 14-week period of weight reduction. Water was available without restriction.

1 Unicap@ (Upjohn), manufacturer's analysis as follows: vitamin A-5000 USP units, vitamin D-500 USP units, ascorbic acid- $37.5 \mathrm{mg}$., thiamine hydrochloride$2.5 \mathrm{mg}$., riboflavin-2.5 mg., pyridoxine hydrochloride$0.5 \mathrm{mg}$., calcium pantothenate- $5.0 \mathrm{mg}$., nicotinamide$20 \mathrm{mg}$., folic acid- $0.25 \mathrm{mg}$., vitamin $\mathrm{B}_{22}-1 \mu \mathrm{g}$. 
TABLE I

Composition of diet

\begin{tabular}{|c|c|c|c|c|c|c|c|}
\hline & $\begin{array}{c}\text { Weight } \\
(\mathrm{gm.})\end{array}$ & $\underset{(\mathrm{em} .)}{\mathbf{P}}$ & $\underset{(s m .)}{F}$ & $\underset{(\mathrm{gm} .)}{\mathrm{C}}$ & $\begin{array}{c}\text { Heat of } \\
\text { combustion* } \\
\text { (cal.) }\end{array}$ & $\begin{array}{l}\text { "Available } \\
\text { calories"† } \\
\text { (cal.) }\end{array}$ & $\underset{(m E q .)}{\mathrm{Na}}$ \\
\hline $\begin{array}{l}\text { Evaporated milk } \\
\text { (The Borden Co.) }\end{array}$ & 525.0 & 35.8 & 41.5 & 51.0 & 725 & 714 & 21.8 \\
\hline $\begin{array}{l}\text { Corn oil } \\
\text { (Corn Products } \\
\text { Refining Co.) }\end{array}$ & 37.5 & - & 37.5 & - & 353 & 332 & - \\
\hline $\begin{array}{l}\text { Dextrose (USP) } \\
\text { Water to }\end{array}$ & $\begin{array}{r}103.5 \\
1,000.0\end{array}$ & - & - & 103.5 & 387 & 381 & - \\
\hline Total & & 35.8 & 79.0 & 154.5 & 1,465 & 1,427 & 21.8 \\
\hline
\end{tabular}

* Specific heat of combustion as calculated (1.38 cal. per gm.) from the results of direct calorimetry. The calorimetric value for evaporated milk was obtained from The Borden Co.; those for corn oil and dextrose were taken from International Critical Tables, New York, McGraw-Hill, 1933.

t"Available calories" computed from the physiological energy factors given by McLester and Darby (6).

During the first period, lasting two to three weeks, the amount of formula was adjusted approximately to maintenance value for each patient. Exact adjustment was unnecessary since the value served only as a baseline for the subsequent alternation of caloric excess and deficit in consecutive four-day periods. During the periods of excess, $55 \mathrm{gm}$. of formula was added to each of the six feedings (485 cal. per day), and during the four days of deficit $55 \mathrm{gm}$. was subtracted from the baseline amount, making the average intake over an eight-day cycle equal to the baseline value. Three of the patients $(A, B, E)$ started with an increment of formula in the initial period, and two (C, D) with a reduction; all of them completed four cycles.

Statistical analysis (described in the Appendix) followed standard methods for analysis of variance which make it possible to divide the variations of weight into three independent components: 1) A trend due to inequality of average caloric intake and expenditure; 2) forced oscillations, correlated with the increases and de- creases of dietary intake; and 3) residual fluctuation, due to any changes in water balance not correlated with the caloric variations and to errors of measurement. The standard error of estimate of course depends upon the relative amplitudes of forced oscillation and random fluctuation; and, in principle, it can be reduced to any desired figure by a suitable choice of the number and length of cycles and the magnitude of caloric variation. In the present work the choice of four cycles of eight days each and a caloric variation of $\pm 485 \mathrm{cal}$. per day represented a compromise between a desire for maximal precision and the necessity of keeping the length of the experiment within practical bounds.

\section{RESULTS}

The data are summarized in Table II. The column headed Average Intake shows the number of calories per day given during the preliminary

TABLE II

The caloric value of labile body tissue in obese subjects

\begin{tabular}{|c|c|c|c|c|c|c|c|c|}
\hline \multirow[b]{2}{*}{$\begin{array}{c}\text { Patient } \\
\text { (RIH No.) }\end{array}$} & \multirow[b]{2}{*}{$\begin{array}{c}\text { Age } \\
\text { (years) }\end{array}$} & \multirow{2}{*}{$\left(\frac{\text { Obesity* }}{\text { mean wt. }}\right)$} & \multirow{2}{*}{$\begin{array}{c}\text { Mean } \\
\text { weight } \\
\text { (kg.) }\end{array}$} & \multirow{2}{*}{$\begin{array}{c}\text { Average } \\
\text { intake } \\
\text { (cal./day) }\end{array}$} & \multirow{2}{*}{$\begin{array}{c}\text { Weight } \\
\text { trend } \\
(\mathrm{gm} . / \mathrm{day})\end{array}$} & \multirow{2}{*}{$\begin{array}{c}\text { Caloric } \\
\text { equivalent } \\
\text { (cal./sm.) }\end{array}$} & \multicolumn{2}{|c|}{ Expenditure } \\
\hline & & & & & & & $\begin{array}{c}\text { Total } \\
\text { (cal./doy) }\end{array}$ & $\begin{array}{c}\text { Per kg. } \\
\text { (cal./kg.day) }\end{array}$ \\
\hline$\underset{14662}{A}$ & 59 & 1.93 & 115.7 & 2,867 & $\begin{array}{l}+21.2 \\
( \pm 3.4)\end{array}$ & $\begin{array}{c}2.16 \\
( \pm 0.26)\end{array}$ & $\begin{array}{c}2,820 \\
( \pm 9)\end{array}$ & $\begin{array}{c}24.4 \\
( \pm 0.08)\end{array}$ \\
\hline$\underset{14622}{B}$ & 45 & 1.78 & 117.3 & 2,867 & $\begin{array}{c}+1.6 \\
( \pm 5.3)\end{array}$ & $\begin{array}{c}2.86 \\
( \pm 0.68)\end{array}$ & $\begin{array}{l}2,862 \\
( \pm 16)\end{array}$ & $\begin{array}{c}24.4 \\
( \pm 0.13)\end{array}$ \\
\hline$\underset{14676}{C}$ & 44 & 2.34 & 154.1 & 2,999 & $\begin{array}{c}-44.2 \\
( \pm 4.9)\end{array}$ & $\begin{array}{c}2.56 \\
( \pm 0.51)\end{array}$ & $\begin{array}{l}3,113 \\
( \pm 26)\end{array}$ & $\begin{array}{c}20.2 \\
( \pm 0.17)\end{array}$ \\
\hline$\underset{14367}{D}$ & 32 & 1.59 & 98.3 & 1,985 & $\begin{array}{l}-31.5 \\
( \pm 2.9)\end{array}$ & $\begin{array}{c}2.46 \\
( \pm 0.28)\end{array}$ & $\begin{array}{l}2,064 \\
( \pm 11)\end{array}$ & $\begin{array}{c}21.0 \\
( \pm 0.12)\end{array}$ \\
\hline$\underset{14389}{E}$ & 16 & 1.65 & 102.3 & 2,029 & $\begin{array}{c}-89.7 \\
( \pm 4.9)\end{array}$ & $\begin{array}{c}3.61 \\
( \pm 1.01)\end{array}$ & $\begin{array}{l}2,359 \\
( \pm 90)\end{array}$ & $\begin{array}{c}23.0 \\
( \pm 0.88)\end{array}$ \\
\hline
\end{tabular}

* "Normal weight" taken from tables of the Association of Life Insurance Directors and Actuarial Society of America, New York, 1912. Cited by Duncan, G. G., Diseases of Metabolism, Philadelphia, W. B. Saunders, 1952, p. 1107. 
TABLE III

Numerical functions for analysis of the trend and the response of weight to caloric imbalance

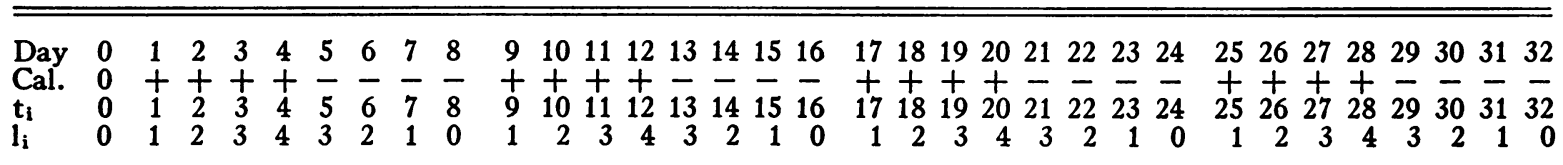

period and continued as an average during the periods of alternation. The Weight Trend is the slope of a linear regression on time, and shows the average daily change of weight due to inequality of caloric intake and output. The Caloric Equivalent is a ratio of caloric variation ( 485 cal. per day) to the correlated change in weight. The product of weight trend and caloric equivalent gives the average daily amount of energy deposited in the body or withdrawn; it is equal to the difference between average intake and the average Expenditure of Energy.

The weight curves given in Figure 1 show considerable random fluctuations of weight, especially

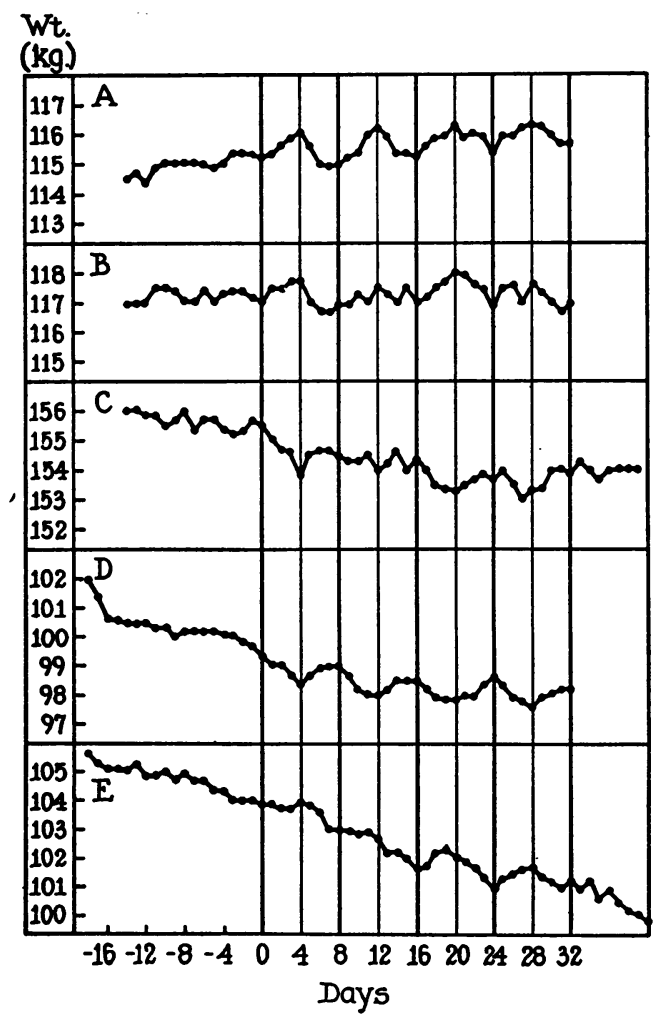

Fig. 1. Dainy Weights

The vertical lines separate the four-day periods of alternating caloric excess and deficit. in the cases of patients $\mathrm{B}, \mathrm{C}$, and $\mathrm{E}$. The caloric equivalent, being a differential coefficient, is highly sensitive to such uncorrelated changes and therefore could be estimated with a precision of only about \pm 25 per cent (Table III). By contrast the average total caloric expenditure, an integral value, could be determined with a precision of better than \pm 1 per cent.

The caloric equivalent for all five patients averaged 2.73. cal. per gm. (Table II). Excluding the datum of the last patient because of the discrepant value, the low precision of estimate, a weight loss during the preceding three months, and marked weight loss during the experiment, we obtain what is possibly a better estimate of the caloric equivalent for stabilized obese subjects, $2.51 \mathrm{cal}$. per gm. The difference is slight, however, and unimportant for present purposes.

The caloric expenditures expressed on a per kilogram basis fell into the range 20.2 to 24.4 cal. per kg. day. Similar values for maintenance of obese women on normal mixed diets have been reported by Harrington (4) and by Brown and Ohlson (5).

It should be noted that the changes in body weight, correlated with the caloric variations, were substantially larger than might be expected from variation of dietary sodium. The ratio of change in amount of dietary sodium to correlated change in body weight was about $37 \mathrm{mEq}$. per $\mathrm{kg}$. Therefore, even if all the extra sodium were retained and diluted to form extracellular fluid, the increment would account for only one-fifth of the observed weight gain.

\section{DISCUSSION}

The caloric equivalent, as measured by alternating periods of dietary excess and deficit, sets an upper limit to the possible caloric value of labile body tissue. In the first place a part, although apparently not a large fraction, of the food energy is lost by partial absorption, excre- 
tion of residues and possibly by irreversible processes in the course of storage. A calculation of "available energy" (6) suggested that about 3 per cent of the heat content of the formula might have been lost in this way (Table I).

More important as an error in the interpretation of caloric equivalent is the probable change in its value with continued excess or deficit of calories. It is well known that glycogen serves as an immediate source of energy and quickly becomes depleted. Benedict's fasting man, for instance, derived relatively little energy from carbohydrate after the third day of starvation (7). Since wet glycogen has a relatively low heat content, 1.72 cal. per gm. (8), and labile tissue protein (9) an even lower value, 0.80 (8), clearly a depletion of these substances would cause the caloric equivalent to rise. Presumably the value measured with four-day periods exceeded the true caloric equivalent of the immediate response.

The low average value found for the equivalent, 2.51 cal. per gm., shows that the primary storage of surplus energy in these obese subjects was associated with the storage of a considerable amount of water. Data in the literature make it probable that this phenomenon is not peculiar to the obese subject, but is of general occurrence. It can be estimated from the data collected by Taylor, Henschel, Mickelsen, and Keys (10), dealing with single periods of acute starvation, that normal men show a caloric equivalent of about 2 cal. per gm. during the first few days without food. Both of these values are far lower than the equivalent of about $8 \mathrm{cal}$. per gm. shown by obese subjects on reduction diets lasting for several weeks (11).

\section{SUM MARY}

1. This paper describes a method for estimating the caloric equivalent of variable weight and the average daily caloric expenditure. The basis of the method is an alternation of dietary intake between surplus and deficit to produce cyclical oscillations of body weight. On statistical analysis, the changes in weight specifically correlated with the dietary variations can be separated from a general trend and from random changes due to fluctuation of water balance and errors of measurement.

2. In the study of five obese women it appeared that the primary reservoirs of energy had a low caloric value per unit weight, probably less than $2.5 \mathrm{cal}$. per gm. This finding was interpreted as evidence that a considerable amount of water is stored and released as a part of the caloric response.

3. The daily requirement for maintenance of patients on a milk formula was 20.2 to 24.4 cal. per kg. day; values similar to these have been reported necessary for maintenance of obese women on normal mixed diets.

\section{APPENDIX}

Assume that the variations of body weight about a mean value can be represented by the sum of three independent components : a linear trend, a linear rise and fall in response to a known increase and decrease of food, and a residual fluctuation due both to uncontrolled physiological factors and to errors of measurement:

$$
\mathrm{W}_{\mathbf{i}}=\mathbf{M}+\mathrm{a} \tau_{\mathbf{i}}+\mathrm{b} \lambda_{\mathbf{i}}+\delta_{\mathbf{i}}
$$

where $W_{i}$ is the measured body weight,

$\tau_{i}$ and $\lambda_{i}$ are functions that have numerical values proportional to the day of experiment and to the stage of cycling, respectively,

$\delta_{i}$ is residual fluctuation, and

$M, a, b$ are the mean, the coefficient of trend and the coefficient of response to caloric imbalance, respectively.

The numerical functions and the fluctuation term are, to a certain extent, arbitrary and can be chosen to have zero means. If this is done their properties are summarized in the following equations, of which the last expresses the independence of trend and the alternation of intake:

$$
M=\frac{1}{n} \Sigma W_{i}, \quad \Sigma \tau_{i}=\Sigma \lambda_{i}=\Sigma \delta_{i}=0, \quad \Sigma \tau_{i} \lambda_{i}=0
$$

where $n$ is the number of observations. Minimizing the residual sum of squares, $\Sigma \delta_{\mathrm{i}}{ }^{2}$, in the usual way, we find the best estimates for $a$ and $b$ :

$$
a=\frac{\Sigma W_{i} \tau_{i}}{\Sigma \tau_{i}^{2}}, \quad b=\frac{\Sigma W_{i} \lambda_{i}}{\Sigma \lambda_{i}^{2}}
$$

For actual calculation, however, it is more convenient to choose integers for the numerical functions and make correction for their non-zero means. The sets $t_{i}$ and $l_{i}$ used in the present analysis are shown in Table III. Their values correspond to an experiment in which the first period is one of caloric surplus; when the experiment started with a deficit the series $l_{i}$ was changed to correspond. In terms of the working functions:

$$
\begin{aligned}
& \mathrm{a}=\frac{\Sigma \mathrm{W}_{\mathrm{i}} \mathrm{t}_{\mathrm{i}}-\overline{\mathrm{t}} \Sigma \mathrm{W}_{\mathrm{i}}}{\Sigma \mathrm{t}_{\mathrm{i}}^{2}-\overline{\mathrm{t}} \Sigma \mathrm{t}_{\mathrm{i}}}=\frac{\Sigma \mathrm{W}_{\mathrm{i}} \mathrm{t}_{\mathrm{i}}-16 \Sigma \mathrm{W}_{\mathrm{i}}}{2992} \\
& \mathrm{~b}=\frac{\Sigma \mathrm{W}_{\mathrm{i}} \mathrm{l}_{\mathrm{i}}-\overline{\mathrm{i}} \Sigma \mathrm{W}_{\mathrm{i}}}{\Sigma \mathrm{l}_{\mathrm{i}}^{2}-\mathrm{i} \Sigma \mathrm{l}}=\frac{\Sigma \mathrm{W}_{\mathrm{i}} \mathrm{l}_{\mathrm{i}}-1.939 \Sigma \mathrm{W}_{\mathrm{i}}}{51.88}
\end{aligned}
$$


The residual error variance, $V_{0}$, is given by:

$$
\begin{aligned}
& 30 \mathrm{~V}_{0}=\left[\Sigma \mathrm{W}_{\mathrm{i}}^{2}-\frac{1}{33}\left(\Sigma \mathrm{W}_{\mathrm{i}}\right)^{2}\right]-\frac{1}{2992}\left[\Sigma \mathrm{W}_{\mathrm{i}} \mathrm{t}_{\mathrm{i}}-16 \Sigma \mathrm{W}_{\mathrm{i}}\right]^{3} \\
& -\frac{1}{51.88}\left[\Sigma W_{i} l_{i}-1.939 \Sigma W_{i}\right]^{2}
\end{aligned}
$$

and the standard errors of the coefficients by:

$$
\sigma_{\mathrm{a}}^{2}=\frac{\mathrm{V}_{\mathrm{e}}}{2992}, \quad \sigma_{\mathrm{b}}^{2}=\frac{\mathrm{V}_{\mathrm{e}}}{51.88}
$$

The caloric equivalent, $\mathrm{E}$ cal. per gm., is given by the ratio of caloric change ( $\Delta$ cal. per day) and weight change (b gm. per day):

$$
\mathrm{E}=\frac{\Delta}{\mathrm{b}}, \quad \sigma_{\mathrm{K}^{2}}=\frac{\Delta^{2} \mathrm{~V}_{0}}{\mathrm{~b}^{4}(51.88)}
$$

The maintenance requirement, $R$ cal. per day, is obtained by subtracting a correction for the trend from the average intake, A cal. per day:

$$
\mathrm{R}=\mathrm{A}-\mathrm{aE}, \quad \sigma_{\mathrm{R}^{2}}=\frac{\Delta^{2} \mathrm{~V}_{0}}{\mathrm{~b}^{2}}\left(\frac{1}{2992}+\frac{\mathrm{a}^{2}}{\mathrm{~b}^{2}(51.88)}\right)
$$

\section{REFERENCES}

1. Atwater, W. O., and Benedict, F. G., A respiration calorimeter with appliances for the direct determination of oxygen. Carnegie Institution of Washington, 1905, Pub. No. 42.

2. Newburgh, L. H., Wiley, F. H., and Lashmet, F. H., A method for the determination of heat produc- tion over long periods of time. J. Clin. Invest., 1931, 10, 703.

3. Ahrens, E. H., Jr., Dole, V. P., and Blankenhorn, D. H., The use of orally-fed liquid formulas in metabolic studies. Am. J. Clin. Nutr., 1954, 2, 336.

4. Harrington, M. M., Appetite in relation to weight. J. Am. Dietet. A., 1930, 6, 101.

5. Brown, E. G., and Ohlson, M. A., Weight reduction of obese women of college age: I. Clinical results and basal metabolism. J. Am. Dietet. A., 1946, 22, 849.

6. McLester, J. S., and Darby, W. J., Nutrition and Diet in Health and Disease. W. B. Saunders, Philadelphia, 1952, p. 626

7. Benedict, F. G., A study of prolonged fasting. Carnegie Institution of Washington, 1915, Pub. No. 203, p. 414.

8. Reifenstein, E. C., Jr., Albright, F., and Wells, S. L., The accumulation, interpretation; and presentation of data pertaining to metabolic balances, notably those of calcium, phosphorus, and nitrogen. J. Clin. Endocrinol., 1945, 5, 367.

9. Madden, S. C., and Whipple, G. H., Plasma proteins : Their source, production and utilization. Physiol. Rev., 1940, 20, 194.

10. Taylor, H. L., Henschel, A., Mickelsen, O., and Keys, A., Some effects of acute starvation with hard work on body weight, body fluids and metabolism. J. Applied Physiol., 1954, 6, 613.

11. Strang, J. M., and Evans, F. A., The energy exchange in obesity. J. Clin. Invest., 1928, 6, 277. 